\title{
Consequences of a flattened morphology: effects of flow on feeding rates of the scleractinian coral Meandrina meandrites
}

\author{
A. S. Johnson*, K. P. Sebens \\ Northeastern University, Marine Science Center, Nahant, Massachusetts 01908, USA
}

\begin{abstract}
The relationships among flow, colony orientation, position of polyps, and capture of particles (hydrated brine shrimp cysts) were examined in the coral Meandrina meandrites using a recirculating flow tank in the 'Aquarius' underwater habitat at St. Croix, U.S. Virgin Islands. Per polyp feeding rate was independent of the horizontal planform area of colonies. At the lowest velocities, most particles were captured on the upstream edge or in the middle of colonies. However, all positional bias in capture rate disappeared at higher velocities. Particle capture and increasing flow speed were negatively associated and there were small, but measurable, differences in mean tentacle length between corals feeding at different velocities. These results suggest that velocity-dependent feeding rate at most velocities was related to changes in flow rather than to changes in feeding behavior. In fact, experiments in which corals were turned upside down revealed that the increased capture rate for rightside-up corals feeding at low velocity could be almost entirely accounted for by gravitational deposition of particles on the corals' tentacles. Examination of flow profiles above and within the tentacles of each coral revealed that the tentacles form a canopy within which water movement was slowed, possibly facilitating gravitational deposition of non-buoyant or sinking food particles. Thus, the orientation of suspension feeders and the velocity of flows they encounter alters the relative success of mechanisms by which they remove particles from flow.
\end{abstract}

\section{INTRODUCTION}

Among current paradigms on the consequences of morphology to feeding success of suspension feeders is one centered around the idea that, as flow increases, there is a trade-off between higher feeding rates associated with the creation of a turbulent wake and greater dislodgement forces due to hydrodynamic drag. The presumption is that the creation of a large, turbulent wake on the downstream side of a suspension feeder both incurs drag and facilitates the capture of food particles that have been slowed and diverted in that area (Leversee 1976, Wainwright et al. 1976 , Warner 1977, Carey 1983, Merz 1984, Okamura 1984.

\footnotetext{
- Present address: Biology Dept, Bowdoin College, Brunswick, Maine 04011, USA
}

1988, Patterson 1984, McFadden 1986, Holland et al. 1987, Johnson 1988, 1990, Helmuth \& Sebens 1993). This type of interaction between morphology and water movement is important to feeding of many vertically oriented suspension feeders (Leversee 1976, Okamura 1984, Holland et al. 1987, Best 1988), as well as to feeding of neighbors downstream of horizontally oriented suspension feeders (Okamura 1988). However, the turbulent wake downstream of a horizontally oriented suspension feeder is less likely to influence its own rates of feeding, because most of the surface area of the organism is positioned out of the plane of its wake (but see Helmuth \& Sebens 1993). We examined the consequences of orientation to feeding success using Meandrina meandrites (Linnaeus, 1758), a scleractinian coral with a flattened or mounding morphology, relatively large polyps, and elongate tentacles. 
Scleractinian corals are morphologically diverse, passive suspension feeders that live in a wide range of flow environments. There is controversy concerning the importance of particle capture to their nutrition, as they are often able to rely on photosynthetic zooxanthellae in their tissues for much of their nutrition. Replenishment of nitrogen, phosphorus, and other nutrients that cannot be supplied from a coral's symbiotic algae, however, must come from zooplankton capture (reviewed by Muscatine 1973, Sebens 1987), and many corals are known to capture zooplankton on a regular basis (Wainwright 1967, Porter 1974, Lewis \& Price 1975, Wellington 1982).

The contribution of tentacle behavior and morphology to feeding rates in corals is unknown. Tentacles are contracted when their primary function (feeding or light capture) is impeded, which suggests that their expansion must involve some form of cost or risk (Porter 1974, Sebens \& DeRiemer 1977). Implicit in this assumption is that the risk of expansion must be offset by a benefit, such as increased feeding. In a given flow environment, long tentacles may be capable of capturing more food than short tentacles (cf. Koehl 1977a), and possibly larger prey. Long tentacles, however, are more likely than short tentacles to deform in fast flow. Deformation of tentacles by fast-moving water is thought to interfere with effective particle capture and retention (Leversee 1976, Okamura 1984, Patterson 1984, McFadden 1986, Shimeta \& Jumars 1991); however, fast flow could increase capture rates by increasing the number of particles per unit time that move past the tentacles and/or by causing the passive reorientation of feeding tentacles into eddy currents on the downstream side of branches (Leversee 1976).

The contribution of the morphology of entire colonies to prey capture by cnidarians has been more widely discussed, especially with respect to orientation to flow (hydroids: Riedl 1971, Harvell \& LaBarbera 1985, Hunter 1989; octocorals: Théodor \& Denizot 1965, Wainwright \& Dillon 1969, Grigg 1972, Rees 1972, Velimirov 1976, Patterson 1980, Best 1988; scleractinians: Chamberlain \& Graus 1975, Graus et al. 1977, Helmuth \& Sebens 1993). Most of these studies have focused on the orientation of upright colonies (those with most of their feeding surfaces perpendicular to flow). Very little is known about the interaction of colony morphology with flow in more horizontally oriented suspension feeders such as Meandrina meandrites (but see Okamura 1985, 1988, Helmuth \& Sebens 1993).

Meandrina meandrites is a common Caribbean coral species that forms broad, low colonies. Typically small (10 to $20 \mathrm{~cm}$ diameter), isolated colonies are round to oval in shape and mounding or flattened
(0 to $6 \mathrm{~cm}$ above the horizontal) in profile. Colonies of $M$. meandrites account for between 0.1 and $1 \%$ of the total cover of corals in Salt River Canyon, St. Croix, U.S. Virgin Islands, at 8 to $40 \mathrm{~m}$ depth, where this study was conducted (Sebens \& Johnson 1991). Polyps are intermediate in size for corals (about $1.0 \mathrm{~cm}$ in diameter of the tentacular crown), and their mouths are surrounded by a thicket of flexible, elongate tentacles ranging in length from 0.5 to $1.0 \mathrm{~cm}$. The relationships among water movement, colony orientation, position of polyps, and capture of particles were examined in this coral using a recirculating flow tank that was installed in the 'Aquarius' underwater habitat at St. Croix. In particular we addressed the following questions: how are feeding rates of the coral $M$. meandrites influenced by the interaction of flow with (1) tentacle length and orientation, (2) colony shape, size, and orientation, and (3) position of feeding polyps on the colony?

\section{MATERIALS AND METHODS}

Field flow measurements. Three Interocean S4 current meters were used to quantify field flow conditions at $0.50 \mathrm{~m}$ off the substratum during a $2 \mathrm{wk}$ saturation in the 'Aquarius' underwater habitat at St. Croix. Meters were used to characterize a highflow site on the East Slope of Salt River Canyon near the 'Aquarius' habitat (15 $\mathrm{m}$ depth) and a lowerenergy site further out along the East Slope $15 \mathrm{~m}$ depth). Vertical pipes sunk into the center of concrete bases each held a flow meter $50 \mathrm{~cm}$ off the bottom. Flow meters collected flow data, sampled at $0.5 \mathrm{~s}$ intervals, for 2 out of every $15 \mathrm{~min}$. Two minutes of flow data equals the passage of about 12 waves. This time interval was chosen as a way of characterizing the habitat given the available memory of the meter, and represents a snapshot of flow in a particular habitat.

Natural diet of Meandrina meandrites. Natural food was collected from $24 \mathrm{M}$. meandrites collected from their natural habitat ( 10 to 20 polyps coral ${ }^{-1}$ ) by placing corals in bowls of $5 \mu \mathrm{m}$ filtered seawater and sucking coelenteron contents into a wide-bore syringe (Sebens 1977, Sebens \& Koehl 1984). As is true of all gut contents, soft-bodied prey are missed, but all crustaceans will be represented in these samples. Samples of prey availability were taken at 5 points ( $10 \mathrm{~cm}$ apart, oriented across flow), 3 to $5 \mathrm{~cm}$ above the same corals using an in situ plankton pump sampler modified from that of Rutzler et al. (1980) (see also Boyd 1973, Sebens \& Koehl 1984) by having separate intake heads $(6 \mathrm{~cm}$ diameter $)$ that could be accurately and rigidly positioned for lateral 
sampling from all directions (methodology described in more detail in Sebens \& Maney 1992). Mesh size was $40 \mu \mathrm{m}$, which would have excluded only the smallest of prey items found in the gut contents (see Table 1). All samples were taken to a surface laboratory immediately following collection. Plankton samples were preserved in $5 \mathrm{ml}$ of $7 \%$ buffered formalin in seawater, and stored flat in Whirl-Pak plastic bags. All samples were examined microscopically. Each recognizable item in the coelenteron contents was recorded and measured (length and width of the primary body excluding fine appendages). To avoid biases in subsampling that could result from different settling velocities of particles of different densities, subsamples were obtained by agitating plankton samples vigorously, without swirling, and removing $6 \mathrm{ml}$ aliquots by rapidly dipping a $6 \mathrm{ml}$ plastic cup to the bottom of the jar during agitation and moving it upward through the sample. These subsamples were placed in petri dishes with gridded bottoms. Counting and measuring began at a blindly selected point and was continued in transects across the whole dish until 200 identifiable zooplankton items were encountered and measured or until the entire sample was examined.

Collection and maintenance of Meandrina meandrites. Whole colonies of $M$. meandrites ranging from 6 to $12 \mathrm{~cm}$ in diameter and 4 to $6 \mathrm{~cm}$ in height were collected from $15 \mathrm{~m}$ depth on the east slope of Salt River Canyon. Divers removed intact corals from the substratum at their base and transferred them undamaged to shelves outside the 'Aquarius' habitat. Corals remained undisturbed on these shelves for at least $24 \mathrm{~h}$ prior to use in experiments inside the underwater habitat.

Laboratory flow tank. Feeding experiments were undertaken in a $150 \mathrm{l}$ recirculating flow tank (similar in design to that of Vogel \& LaBarbera 1978). The body of the tank was rectangular $(80 \mathrm{~cm}$ long $\times 20 \mathrm{~cm}$ wide $x$ $30 \mathrm{~cm}$ high) and flow was recirculated through a $15 \mathrm{~cm}$ external diameter pipe.

Flow speed was measured by the following 2 methods: (1) particles moving at $4 \mathrm{~cm}$ above the bottom were timed visually over a distance of $10 \mathrm{~cm}$. This technique was used to determine ambient velocity in the flow tank at the end of each experiment. Such measurements were made 7 to 11 times for each experimental run. All experiments described below were conducted within flow categories of around 3, 5, 10, 15 , and $25 \mathrm{~cm} \mathrm{~s}^{-1}$. Means, standard errors (SE), and sample sizes (n) for each flow category (measured as described above) were as follows: $3.18 \mathrm{~cm} \mathrm{~s}^{-1}(\mathrm{SE}=0.06, \mathrm{n}=70)$; $5.00 \mathrm{~cm} \mathrm{~s}^{-1}(\mathrm{SE}=0.17, \mathrm{n}=50) ; 9.3 \mathrm{~cm} \mathrm{~s}^{-1}(\mathrm{SE}=0.12$, $\mathrm{n}=36) ; 15.4 \mathrm{~cm} \mathrm{~s}^{-1}(\mathrm{SE}=0.27, \mathrm{n}=30) ; 24.7 \mathrm{~cm} \mathrm{~s}^{-1}$ $(\mathrm{SE}=0.69, \mathrm{n}=41)$.
(2) Particles moving with the water in the flow tank in a plane illuminated by a $0.1 \mathrm{~cm}$ slit of light were photographed in the working area of the flow tank (40 $\mathrm{cm}$ downstream of the flow straighteners) with a $35 \mathrm{~mm}$ camera using long exposures of $1 / 2,1 / 4,1 / 8$, and $1 / 15 \mathrm{~s}$ ( $\mathrm{f}=2.8$; Kodak Tri-X film; Johnson 1986 , 1988). The length of the particle streaks that appeared on photographs were measured to determine the speed of particles moving during each exposure. The only particles measured were those that, during the course of the exposure, moved in a straight line and stayed in focus in the area lighted by the slit. This technique was used (a) to calibrate the settings on the flow tank, (b) to determine the velocity profile of the flow tank, and (c) to determine flow speed at different locations relative to the coral during the course of an experiment

Undisturbed flow in the working area $(40 \mathrm{~cm}$ downstream of the flow straighteners) was laminar, and maintained a constant mainstream velocity above $2 \mathrm{~cm}$ from the bottom of the tank (Fig. 1). Flow depth was kept constant at $20 \mathrm{~cm}$.

Feeding experiments. Dry brine shrimp cysts $(200$ to $250 \mu \mathrm{m}$ diameter) were hydrated for about $2 \mathrm{~h}$ prior to use in experiments $(1 \mathrm{ml}$ dry cysts in $100 \mathrm{~m}$ ] filtered seawater). Brine shrimp cysts are well within the size range of particles ingested by Meandrina meandrites (see Table 1). After $2 \mathrm{~h}$ most cysts were observed to be either close to neutrally buoyant (floating in the middle of the container) or slightly negatively buoyant (sank slowly after being stirred up). Although the same concentration of cysts was added to the flow tank to start each experiment, cyst density was determined independently at the end of each experiment. To do this, three to five $20 \mathrm{ml}$ samples of seawater were removed from the flow

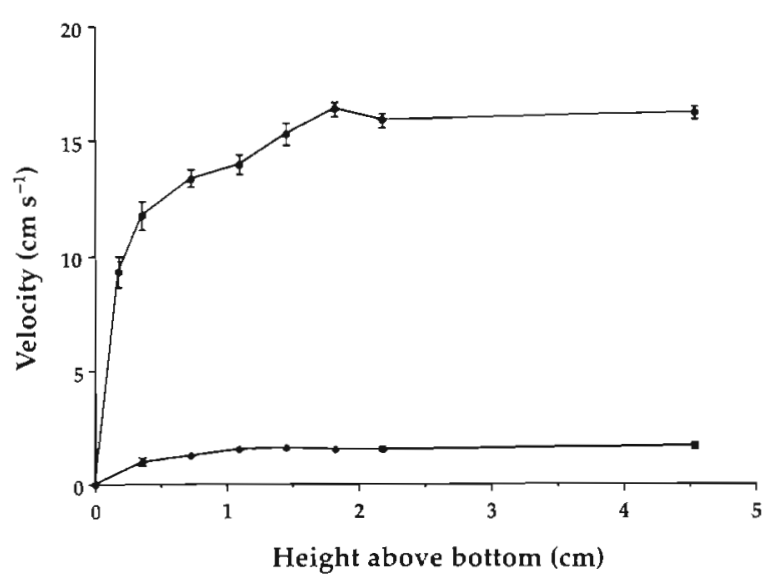

Fig. 1. Velocity in the flow tank as a function of height above bottom for 2 different mainstream velocities ( 3 and $15 \mathrm{~cm} \mathrm{~s}^{-1}$ ). Error bars represent $1 \mathrm{SE}$ 

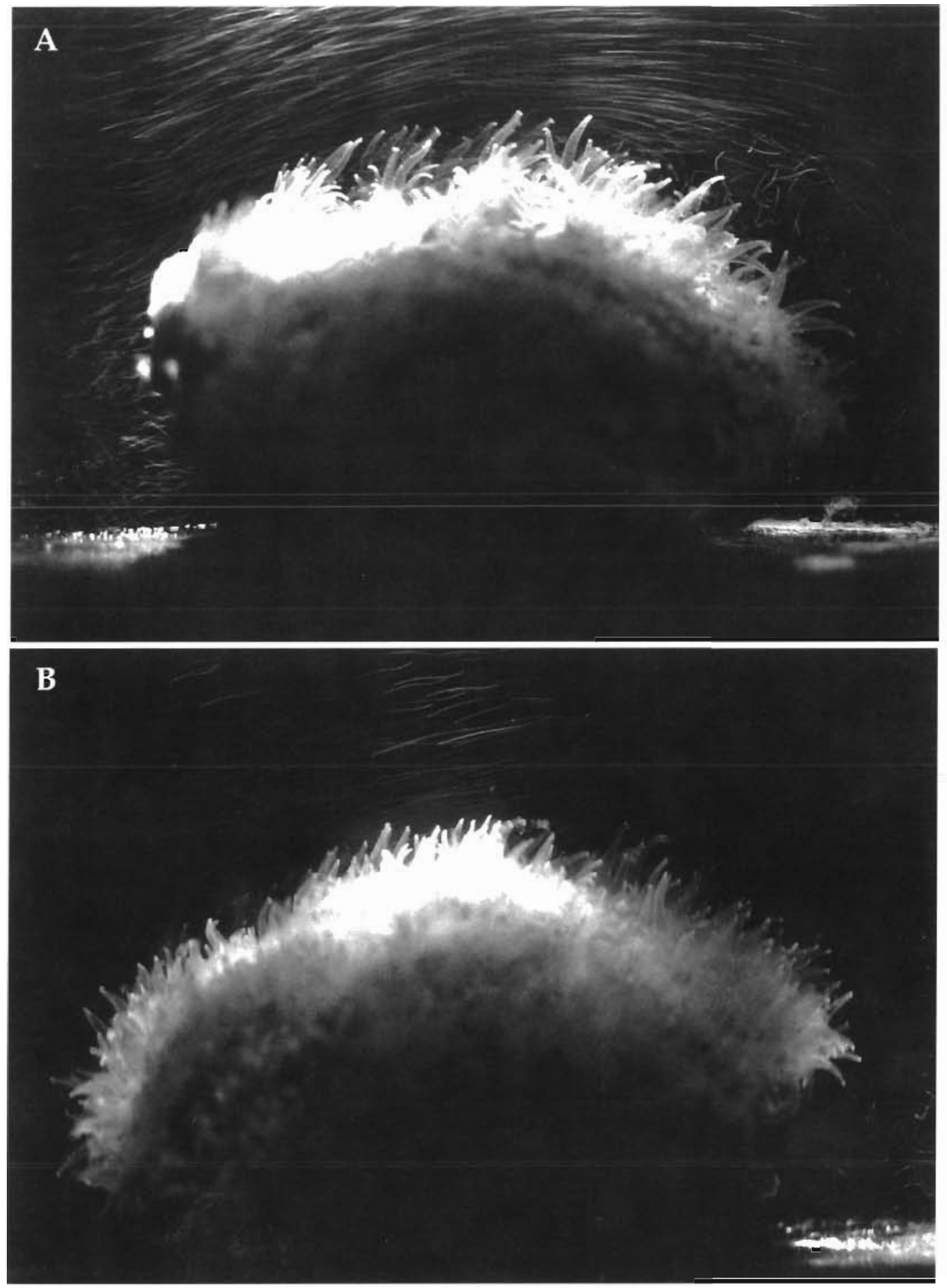

Fig. 2. Meandrina meandrites. Long-exposure photographs $(0.25 \mathrm{~s})$ of flow over 2 animals feeding at an ambient velocity of $5 \mathrm{~cm} \mathrm{~s}^{-1}$ Flow direction from left to right. Corals A \& B were ca $9 \mathrm{~cm}$ and $11 \mathrm{~cm}$ long, respectively. The length and orientation of streaks on the photographs provide a 2-dimensional representation of the speed and direction of flow over the middle region (illuminated by a narrow slit of light) of these colonies. Longer streaks indicate higher speeds. Dots are particles that did not move during the photographic exposure. Note that streaks and dots also appear within the array of tentacles 
tank using a $50 \mathrm{ml}$ syringe. The syringe was held with its open end facing upstream at a height of $4 \mathrm{~cm}$ above the bottom in the area of the flow tank previously occupied by the experimental coral. Water was pulled into the syringe at as close to the same flow rate as was possible to ascertain by eye, and the number of cysts in each $20 \mathrm{ml}$ sample was counted. It should be noted that removal of the corals at the end of each experiment stirred up cysts deposited on the bottom during each trial. There was no association between concentration of available cysts and velocity (regression analysis: $p_{(1,20)}=0.78$ ).

Several hours prior to their use in feeding experiments, corals were transferred to darkened holding tanks containing filtered seawater. This was considered as sufficient time for gut passage of any food the corals might have eaten prior to this transfer (Porter 1974, Sebens 1987). All experiments were run after dusk because tentacle extension during the daylight hours is generally incomplete. Animals were positioned $40 \mathrm{~cm}$ downstream of the flow straighteners. Their lowest tentacles were generally $>1.5 \mathrm{~cm}$ above the bottom (e.g. Fig. 2). The entire tank was covered in black plastic so feeding by the corals would not be disturbed by ambient light. Individual corals were transferred to the flow tank 20 min prior to the initiation of each experiment.

Flow was maintained at the experimental velocity during this acclimation period. If all tentacles appeared to be fully extended after $20 \mathrm{~min}$ then the experiment was initiated by adding the hydrated brine shrimp cysts upstream of the flow straighteners. Corals were allowed to feed for a total of $15 \mathrm{~min}$. They were left undisturbed and in the dark for the first $7 \mathrm{~min}$ of each trial. At $7 \mathrm{~min}$ the flow tank was briefly illuminated through a narrow slit to take 3 longexposure photographs (see Fig. 2 for an example) and $10 \mathrm{~s}$ of video recordings (Sony V9 $8 \mathrm{~mm}$ camcorder). No tentacle contraction was observed during this brief illumination. Photographs and videotapes were for use in determining local velocities around the corals and the extension of their tentacles. The corals were left undisturbed and in the dark for the remainder of the trial. Trials were ended by touching the surface of the coral to cause tentacle retraction and cessation of feeding.

After a light rinsing in filtered seawater to remove any uncaptured cysts that may have adhered to the surface of the colony, colonies were placed in bowls of $40 \mu \mathrm{m}$ filtered seawater. Capture of brine shrimp cysts was quantified by counting them after their removal from the coelenteron of individual polyps with a wide-bore syringe. Maps were made marking the location of each polyp in the entire colony. Individual polyps were assigned a position on the coral as fol- lows: A polyp's mouth was designated as 'upstream' or 'downstream' if some portion of the coral surface surrounding that mouth occurred right on the upstream or downstream edge, respectively; a polyp's mouth was designated as 'middle' if it was surrounded on all sides by other polyps; all other mouths were designated as 'side'. Horizontal planform area (projected horizontal area parallel to flow) of each colony was determined from measurements of their length and width, using the formula for the area of an ellipse.

To investigate feeding rates in the absence of gravitational deposition (particle settlement) onto the corals, feeding experiments were repeated at the lowest flow speed of $3 \mathrm{~cm} \mathrm{~s}^{-1}$ for corals oriented upside down. Tips of upside down corals were $>2 \mathrm{~cm}$ from the bottom of the tank. Mainstream flow for corals feeding upside down did not differ significantly from that of corals feeding rightside-up at $3 \mathrm{~cm} \mathrm{~s}^{-1}$ (t-test: $\mathrm{p}_{(68)}=0.69$ ).

The water temperature in the flow tank was $20^{\circ} \mathrm{C}$ $\left( \pm 1^{\circ} \mathrm{C}\right)$ for all experiments. Water used in the flow tank was removed directly from the water surrounding the habitat just prior to each experimental run. Therefore $20^{\circ} \mathrm{C}$ was representative of temperatures at the depth of the 'Aquarius' habitat during the time of the experiments.

Standardization of capture rate. Although the mean number of cysts $\mathrm{ml}^{-1}$ did not differ significantly among flow categories (ANOVA: $p_{(4.17)}=0.29_{i}$ mean density $=1.1$ cysts $\mathrm{ml}^{-1}, \mathrm{SD}=0.37$ ), there were significant differences between trials within flow categories. Therefore, all cyst capture data were standardized using the formula $S=s M / A$, where $S=$ standardized number of cysts captured by each individual polyp; $s=$ actual number of cysts captured by each individual polyp; $M=$ maximum number of cysts per volume available to be captured among the experimental trials (a constant in the equation) and $A=$ number of cysts per volume available to be captured for each experimental colony (calculated for each colony as described above).

Appropriateness of the flow tank. Every test of flow and feeding in flow tanks involves some obstruction of that tank by the study object. Vogel (1981) and Denny (1988) have argued that if the projected area of an object occludes less than $10 \%$ of the cross-sectional area of the tank, then tank effects can be considered negligible. The projected area perpendicular to flow (estimated from dimensions by the formula for a half ellipse) of the 2 largest corals used in this study occluded $13 \%$ of the crosssectional area of the tank; the remaining 29 corals used in this study fell below $9 \%$ of the crosssectional area of the tank (including the area that 
would be occluded by extended tentacles). The $10 \%$ rule is useful because, as a result of the principle of continuity, the $10 \%$ rule implies that, on average, the flow in the tank cross-section containing the object is not speeded up by more than $11 \%$ due to tank effects.

Notwithstanding the $10 \%$ rule, parts of a coral may be close enough either to the surface of the water or to the sides of the tank to alter flow in those regions. Nowell \& Jumars (1984) assert that if the surface of the water is less than 3 heights above the object serious flow artifacts will occur. Even the tallest coral $(6 \mathrm{~cm}$ high) was more than 3 coral heights away from the surface; therefore, surface effects are negligible in this study. For side wall effects, Nowell \& Jumars (1984) suggest that if the object occupies more than $25 \%$ of the channel width then side walls will alter flow around the sides of the object relative to a comparable field situation. At their widest point, our corals occupied 30 to $60 \%$ of the width of the tank. However, corals are semielliptical in cross-section. Although their widest point may occupy $60 \%$ of the tank, the average width of the largest coral only occupied $36 \%$ of the width of the tank, all other corals occupied less. The average width is probably more relevant than the maximum width in determining how much flow will tend to go over rather than around the coral as a consequence of artifacts. Nevertheless, in the next section we experimentally consider the potential contribution of the side wall of the tank in more detail.

Side walls could either accelerate or decelerate flow around the sides of the corals. For example, if a given volume of water moves through a relatively small space adjacent to the corals then flow will accelerate around the side of objects (principle of continuity). Alternatively, if the resistance created by the proximity of the object to the wall is high enough to cause water to move around rather than through the area adjacent to the side of the object then flow might decelerate around the side of the corals. To examine the magnitude of flow alteration around the sides of corals we compared flow over the top of model corals with that around the sides.

Experiments to determine side wall effects on flow were conducted in a flow tank of the same design and dimensions as used in the feeding experiments. Two models were constructed (Fig. 3) to be the same dimensions as the largest coral $(12 \mathrm{~cm}$ diameter, 6 $\mathrm{cm}$ tall) and smallest ( $6 \mathrm{~cm}$ diameter, $4 \mathrm{~cm}$ tall) corals used in the feeding experiments described above. Tentacle length, width, and density were determined from photographs of living corals used in the feeding experiments. Coral skeletons were modelled from air drying clay (Das Pronto) coated with urethane sealant (Zip-guard) to prevent dissolution of the hardened clay when immersed in water. Tentacles were made from $1 \mathrm{~cm}$ long elastic bands, which approximated the width $(0.15 \mathrm{~cm})$ and flexibility of living tentacles. These elastic tentacles were embedded in the model skeletons before drying the clay.

Flow was quantified around these models using hydrated brine shrimp cysts as described above. Longexposure photographs were taken at 2 mainstream velocities: $4.8 \mathrm{~cm} \mathrm{~s}^{-1}(\mathrm{SE}=0.10)$ and $15.8 \mathrm{~cm} \mathrm{~s}^{-1}(\mathrm{SE}=$ 0.18). Photographs were taken from the side of the tank at 2 different locations by changing the position of the narrow slit of light that illuminated the tank and models as follows: (1) at the midline of the models (the middle of the tank) and (2) $7 \mathrm{~cm}$ from the side wall of the tank. To compare mean flow speeds at the sides versus the tops of these corals, streak lengths, located $1 / 3$ to $2 / 3$ along the length of the coral and at heights between $0.1 \mathrm{~cm}$ and $4 \mathrm{~cm}$ above the surface of the corals, were measured off these photographs.

ANOVA was used to compare flow in these regions with each other as well as to mainstream flow in the tank. Since flow was generally slowed near the surface of the coral, only values outside of this region of slowing (usually $>1 \mathrm{~cm}$ above the coral; Fig. 4) were used in the ANOVA. Mainstream flow used for this comparison was measured, in the absence of any models, at the same horizontal location in the tanks as the model corals and at a height above the bottom equivalent to between 1 and $4 \mathrm{~cm}$ above the model corals.

Unplanned tests. When ANOVA revealed significant differences among several groups, it was followed by Fisher's PLSD and the Scheffé F-test, 2 a posteriori tests designed to determine more specific differences between groups. When the data were significant $(p<0.05)$ by only 1 test it was always Fisher's PLSD and in those situations only Fisher's PLSD is cited; when both tests gave a significance of $p<0.05$, the Scheffé $F$-test is cited.

\section{RESULTS AND DISCUSSION}

\section{Flow in the field}

Fig. 5 presents summary data comparing means and standard deviations of flow speeds taken over ten $4 \mathrm{~h}$ periods ( $\mathrm{n}=960$ half-second data points $\mathrm{h}^{-1}$ ) at 2 sites in Salt River Canyon near colonies of Meandrina meandrites. Data used in Fig. 5 were square root transformed (normalized) before analysis because the frequency distributions of instantaneous $(0.5 \mathrm{~s})$ speeds were skewed toward the lower values. Square root transformation normalizes a Poisson distribution for 


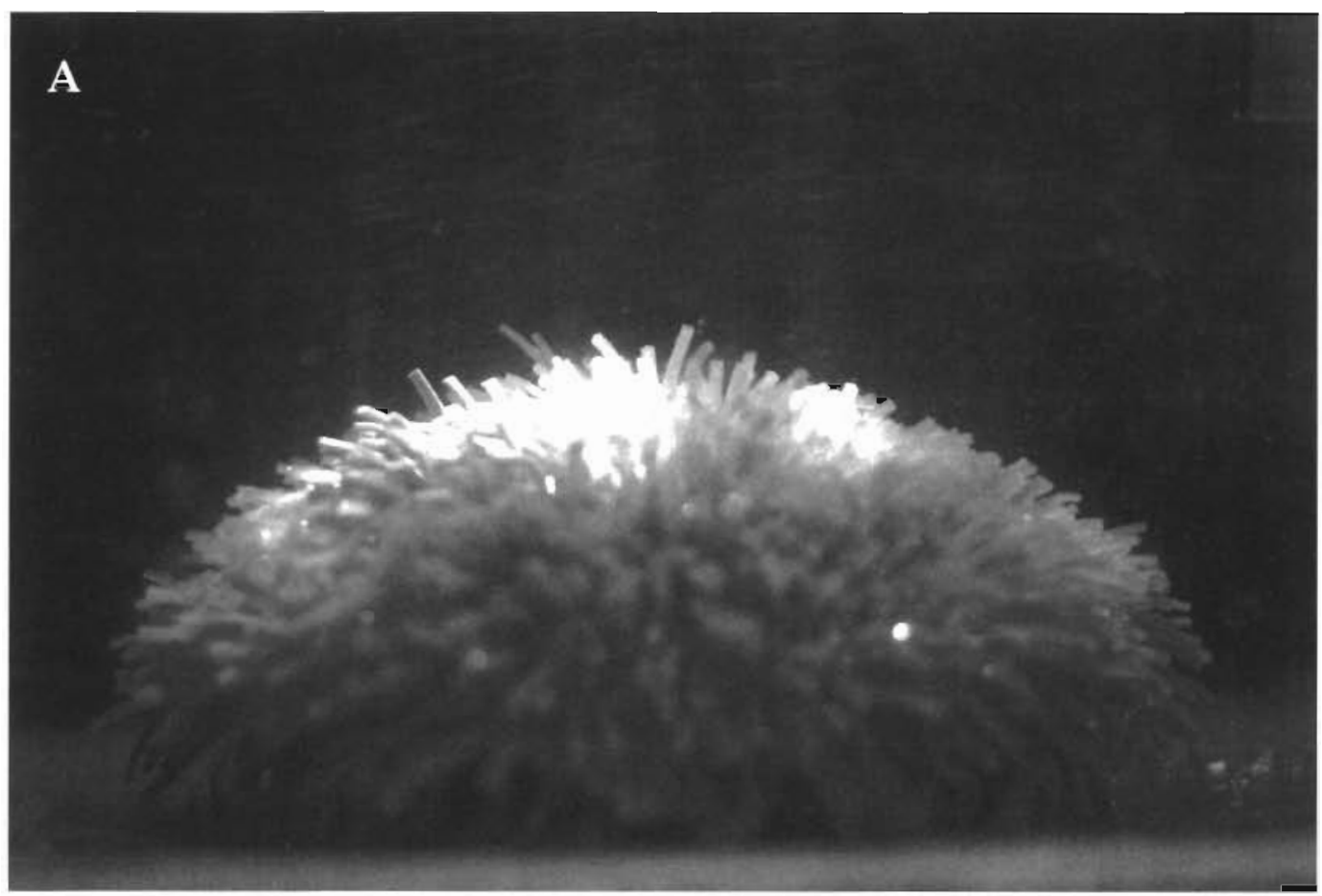

B

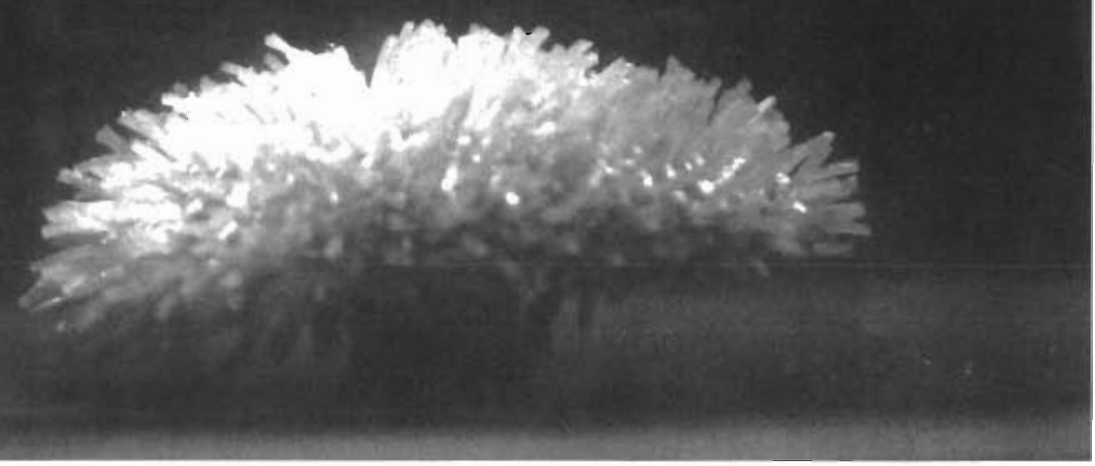

Fig. 3. Meandrina meandrites. Photograph of a (A) large and a (B) small model of the coral (compare to living corals in Fig. 2). Height of large model (including tentacles) is $6 \mathrm{~cm}$, of small model is $4 \mathrm{~cm}$

purposes of descriptive statistics (Sokal \& Rohlf 1981). The data were then back-transformed to represent real values for the means and standard deviations used in Fig. 5. This method produces assymetrical error bars that provide a more accurate illustration of withinsample variance than would result from using nontransformed data. Mean flow at $15 \mathrm{~m}$ depth was always near or above $10 \mathrm{~cm} \mathrm{~s}^{-1}$ at the inner near habitat site 
A

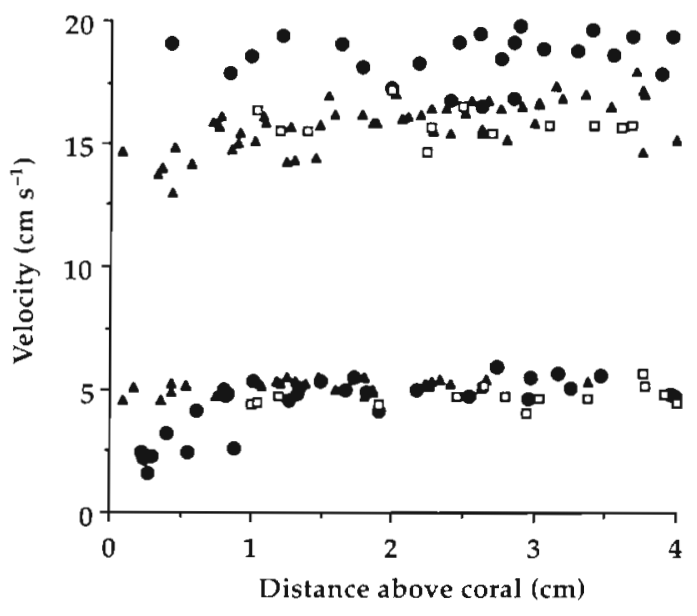

B

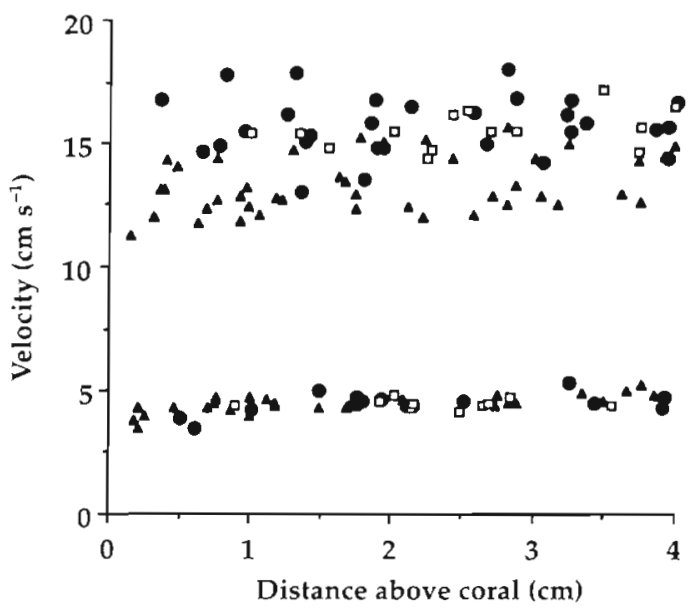

Fig. 4. Meandrina meandrites. Velocity $\left(\mathrm{cm} \mathrm{s}^{-1}\right)$ as a function of height $(\mathrm{cm})$ above a $(\mathrm{A})$ large and a (B) small model of the coral. Velocity was determined over the top (1) and at the sides ( $\Delta$ ) of the model corals and in the absence of models (ㅁ) at a fast $\left(15.8 \mathrm{~cm} \mathrm{~s}^{-1}\right)$ and a slow $\left(4.8 \mathrm{~cm} \mathrm{~s}^{-1}\right)$ ambient velocity. See text for details of statistical comparisons

compared to mean flow at or below $8 \mathrm{~cm} \mathrm{~s}^{-1}$ at the outer site over this $40 \mathrm{~h}$ period ( 20 to 22 July 1988 ). Some of these days included periods of moderately strong waves.

An example of typical conditions during our study is shown in Fig. 6, which illustrates speed and direction of flow over a 2 min sampling period with samples taken at half-second intervals (20 July 1988). Although mean speed was around $11 \mathrm{~cm} \mathrm{~s}^{-1}$, a wide range of flow speeds occurred during this sampling period (2 to $32 \mathrm{~cm} \mathrm{~s}^{-1}$ ). Flow was primarily wave-induced oscillatory flow and was thus strongly bidirectional along the NNE-SSW axis at both sites. Colonies found at depths greater than $15 \mathrm{~m}$ experience slower, sometimes unidirectional flow (Sebens \& Johnson 1991).

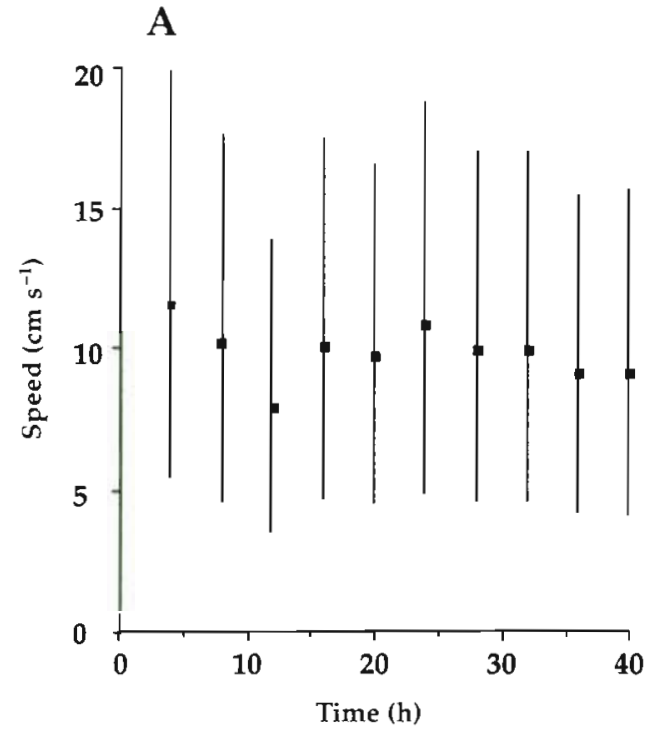

B

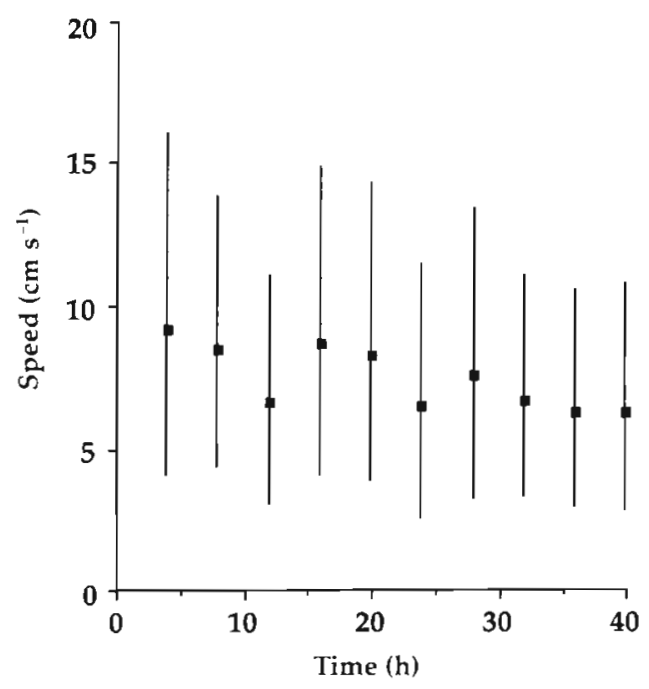

Fig. 5. Summary data comparing mean and standard deviations of flow speeds $\left(\mathrm{cm} \mathrm{s}^{-1}\right)$ (15 $\mathrm{m}$ depth) taken over ten $4 \mathrm{~h}$ periods (horizontal axis; $n=960$ per hour) at (A) the east slope near the habitat, and (B) the outer east slope in Salt River Canyon

\section{Meandrina meandrites capture a variety of prey}

Coelenteron contents of 24 Meandrina meandrites (10 to 20 polyps coral ${ }^{-1}$ ) are shown in Table 1 . Although $M$. meandrites ingested a wide variety of prey items, more than $95 \%$ of prey were large copepods and foraminiferans. Capture of prey generally appears to reflect prey availability (Tables $2 \& 3$ ), as more than $85 \%$ of available zooplankters were also large copepods and foraminiferans. Among the copepods, however, there appeared to be a dramatic overrepresenta- 

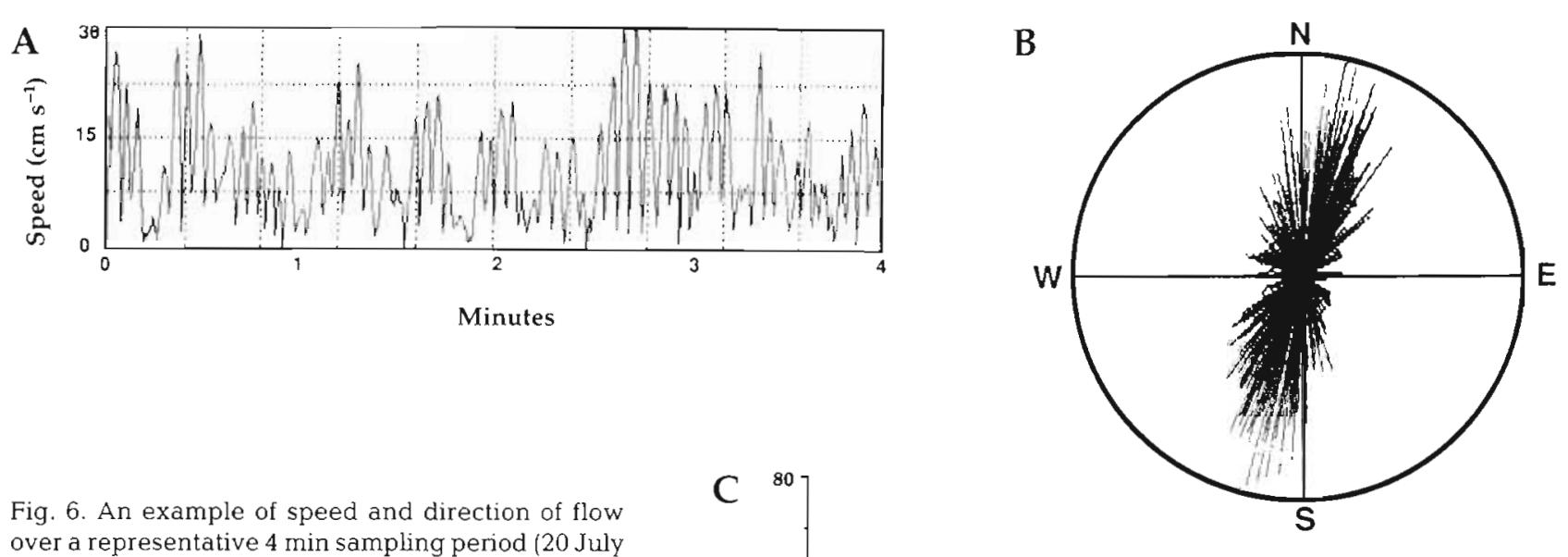

Fig. 6. An example of speed and direction of flow over a representative 4 min sampling period (20 July 1988) at the east slope site (15 $\mathrm{m}$ depth) near the underwater habitat; samples were recorded in instantaneous mode each half second (Interocean S4 current meter). (A) Speed over a $4 \mathrm{~min}$ interval, showing oscillations due to waves passing over the site (period of oscillation 6 to $7 \mathrm{~s}$ ). (B) Polar diagram of flow speed and direction (maximum flow $32 \mathrm{~cm}$ $\mathrm{s}^{-1}$ ) for the same data as in (A), showing the primarily bidirectional nature of flow at this site. (C) Flow speed frequency plot of data in (A), indicating the number of half-second intervals during which each speed was recorded. Mean speed was $11 \mathrm{~cm} \mathrm{~s}^{-1}$

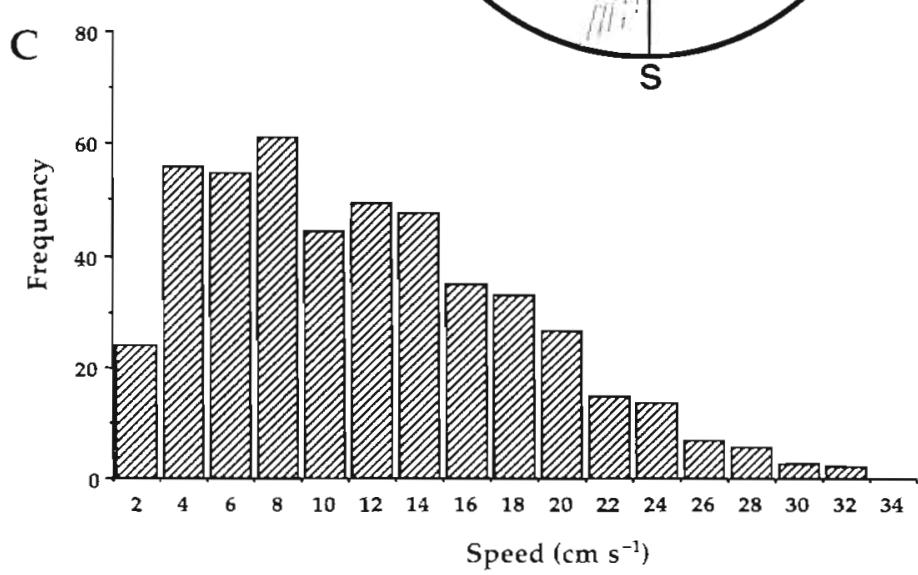

tion of the large calanoid copepod Calanopia sp. relative to its abundance $(3.4 \%$ of plankton sample versus $75 \%$ of coelenteron contents) and underrepresentation of the smaller cyclopoid copepod Oithona sp. relative to its abundance ( $75.1 \%$ of plankton sample versus $18.5 \%$ of coelenteron contents).
Table 1 Coelenteron contents of 24 Meandrina meandrites (10 to 20 polyps coral $^{-1}$ ) collected July 1988, Salt River Canyon, St. Croix. Size range is that of the organisms' longest dimension

\begin{tabular}{|lccc|}
\hline Prey items & Number & Percent & Size range $(\mu \mathrm{m})$ \\
\hline Copepods & 567 & 95.1 & $431-1353$ \\
Harpacticoid & 13 & 2.0 & $720-1200$ \\
Cyclopoid (Oithona sp.) & 110 & 18.5 & $431-723$ \\
Calanoid (Calanopia sp.) & 444 & 74.7 & $923-1353$ \\
Amphipods & 1 & 0.2 & 660 \\
Crab zooea & 1 & 0.2 & 100 \\
Crab megalops & 1 & 0.2 & 90 \\
Shrimp (decapod) & 2 & 0.3 & $300-2400$ \\
Ostracods & 8 & 1.3 & $60-200$ \\
Nauplii & 2 & 0.3 & $16-43$ \\
Bivalve veligers & 1 & 0.2 & - \\
Gastropod veligers & 2 & 0.3 & - \\
Invertebrate eggs & 1 & 0.2 & 694 \\
Nematodes & 3 & 0.5 & $21-10114$ \\
Polychaetes & 5 & 0.8 & $41-79$ \\
Foraminiferans & $60^{\text {a }}$ & - & $3-360$ \\
Sponge spicules & Common & - & - \\
Crustacean fragments & Numerous & - & - \\
a Some may be shells only, not used in percent calculation & \\
\hline
\end{tabular}

\section{Magnitude of side wall effects in the flow tank}

Flow always accelerates around objects, even in the absence of nearby walls and surfaces [Nowell \& Church 1979, Eckman et al. 1981, Johnson 1986, see also Vogel 1981 for a description of acceleration of flow over objects (Bernoulli Principle)]. At an ambient velocity of $4.8 \mathrm{~cm} \mathrm{~s}^{-1}$ ( $\left.\mathrm{SE}=0.10\right)$ there was a significant increase in velocity at the top and side of the large model coral when compared to mainstream flow in the absence of models (ANOVA: $\mathrm{p}_{(2,52)}=$ $0.0009 ;$ mean $_{\text {top }}=5.1 \mathrm{~cm} \mathrm{~s}^{-1}, \mathrm{SE}=0.10$; mean $\left._{\text {side }}=5.2 \mathrm{~cm} \mathrm{~s}^{-1}, \mathrm{SE}=0.05\right)$ but not around the small model coral (ANOVA: $\mathrm{p}_{(2,35)}=0.59 ;$ mean $_{\text {top }}=4.6 \mathrm{~cm} \mathrm{~s}^{-1}, \mathrm{SE}=$ $0.09 ;$ mean $_{\text {side }}=4.7 \mathrm{~cm} \mathrm{~s}^{-1}, \mathrm{SE}=0.08$; Fig. 4). There were, however, no significant differences in flow speed over the 
Table 2. Samples of prey availability, collected 15 to 24 July 1988, Salt River Canyon, St. Croix, for organisms found in the coelenteron of Meandrina meandrites (see Table 1). Results represent mean number per $100 \mathrm{l}$, averaged from 22 samples; standard deviation shown in parentheses after the mean. Size range is that of the organisms' longest dimension

\begin{tabular}{|c|c|c|c|}
\hline Prey items & Mean number & Percent & Size range $(\mu \mathrm{m})$ \\
\hline Copepods & 4890 & 87.6 & \\
\hline Harpacticoids & $257(447)$ & 4.5 & 220 \\
\hline Microsetella sp. & 63 & 1.1 & $220-600$ \\
\hline Macrosetella gracilia & 29 & 0.6 & $640-1040$ \\
\hline Others & 161 & 2.8 & $240-1400$ \\
\hline Cyclopoids $^{a}$ & $4285(8131)$ & $76.8^{a}$ & $300-800$ \\
\hline Oithona spp. & 4193 & 75.1 & $300-800$ \\
\hline Calanoids $^{a}$ & $351(602)$ & $6.3^{\mathrm{a}}$ & $300-3420$ \\
\hline Calanopia sp. & 190 & 3.4 & $1100-1360$ \\
\hline \multicolumn{4}{|l|}{ Amphipods } \\
\hline Gammarid & $11(23)$ & 0.2 & $564-2640$ \\
\hline Caprellid & $151(30)$ & 2.7 & - \\
\hline Crab zooea & $52(6)$ & 0.9 & - \\
\hline Crab megalops & 0 & 0 & - \\
\hline Shrimp (decapod) & $15(33)$ & 0.3 & $1260-4800$ \\
\hline Ostracods & $84(160)$ & 1.5 & $72-456$ \\
\hline Nauplii & $168(276)$ & 3.0 & $50-700$ \\
\hline Veligers & $48(106)$ & 0.9 & $96-384$ \\
\hline Pediveligers & $0.5(2.2)$ & 0.009 & - \\
\hline Invertebrate eggs & $93(67)$ & 1.2 & $36-264$ \\
\hline Nematodes & $11(31)$ & 0.2 & $324-1640$ \\
\hline Polychaetes & $19(36)$ & 0.3 & $600-4724$ \\
\hline Foraminiferans & $1618(1932)^{\mathrm{b}}$ & - & - \\
\hline Sponge spicules & Common & - & - \\
\hline \multicolumn{4}{|c|}{$\begin{array}{l}\text { ¿Cyclopoid and calanoid copepods not found in the coelenteron are } \\
\text { listed in Table } 3\end{array}$} \\
\hline \multicolumn{4}{|c|}{${ }^{\mathrm{b}}$ Some may be shells only, not used in percent calculation } \\
\hline
\end{tabular}

Flow accelerated above and decelerated between Meandrina meandrites tentacles

Analysis of a series of photographs for 1 coral feeding at an ambient velocity of $5 \mathrm{~cm}$ $\mathrm{s}^{-1}$ revealed that the measured component of flow (i.e. determined from particles that, during the course of the exposure, moved in a straight line and stayed in the area lighted by the slit) decelerated relative to mainstream speeds by as much as $75 \%$ as water moved downstream below the tentacles of the coral, and accelerated relative to mainstream speeds by as much as $25 \%$ as water moved downstream above the coral (>1.5 cm above, not including the wake; Fig. 7). At all these midline positions (upstream, middle, downstream) flow was significantly slower below the tentacle tips than above them.

\section{Tentacles were most extended at an intermediate velocity}

Tentacles of Meandrina meandrites were more extended on corals feeding at $5 \mathrm{~cm} \mathrm{~s}^{-1}$ than in the slowest $\left(3 \mathrm{~cm} \mathrm{~s}^{-1}\right)$ and fastest flow (25 $\mathrm{cm} \mathrm{s}^{-1}$; Fig. 8A). Tentacle length did not differ between corals which fed rightside-up and those which fed upside down at $3 \mathrm{~cm} \mathrm{~s}^{-1}$ (Fig. 8B). This last result suggests that the feeding behavior of upside down and rightside-up corals was equivalent with respect to tentacle extension. There was some variation in orientation of tentacles at $5 \mathrm{~cm} \mathrm{~s}^{-1}$ (Fig. 2A, B); however, upstream tentacles generally became flattened against the colony (e.g. Fig. 2A) at velocities $\geq 5 \mathrm{~cm} \mathrm{~s}^{-1}$

\section{Gravitational deposition increased capture rate at lowest velocity}

There was a negative association between per polyp cyst capture and increasing flow speed for corals oriented rightside-up (Fig. 9A). Similarly, there was a negative association between per colony cyst capture and increasing flow speed $\left(R^{2}=0.27 ; p_{(i, 19)}=0.016\right)$. Feeding rate of upside down corals was $75 \%$ less than that of corals oriented rightside-up at $3 \mathrm{~cm} \mathrm{~s}^{-1}$ (Fig. 9B). Further, when capture by gravitational deposition was factored out at $3 \mathrm{~cm} \mathrm{~s}^{-1}$ by turning the corals upside down, then capture rate was no longer significantly different than that of corals feeding rightside-up at conclusions of this study 
Table 3. Samples of prey availability, collected 15 to 24 July 1988, Salt River Canyon, St. Croix, for plankton not found in the coelenteron of Meandrina meandrites. Results represent mean number per $100 l_{\text {, averaged from }}$ 22 samples; standard deviation shown in parentheses after the mean. Size range is that of the organisms' longest dimension

\begin{tabular}{|c|c|c|c|}
\hline Prey items & Mean number & Percent & Size range $(\mu \mathrm{m})$ \\
\hline \multicolumn{4}{|l|}{ Copepods } \\
\hline \multicolumn{4}{|l|}{ Cyclopoids ${ }^{\text {a }}$} \\
\hline Corycaeus $\mathrm{sp}$ & 35 & 0.6 & $320-800$ \\
\hline Oncaea sp. & 43 & 0.8 & $460-600$ \\
\hline Sapphirilla sp. & 15 & 0.3 & 800 \\
\hline \multicolumn{4}{|l|}{ Calanoids $^{a}$} \\
\hline Other calanoids & 146 & 2.6 & $300-1080$ \\
\hline Labidocera sp. & 15 & 0.3 & \\
\hline Trochophore (polychaete) & $14(30)$ & 0.2 & $240-1020$ \\
\hline Pteropod & $14(18)$ & 0.2 & $120-480$ \\
\hline Ascidian larvae & $9(16)$ & 0.2 & $240-768$ \\
\hline Mysids & $4(11)$ & 0.07 & $1625-4800$ \\
\hline Flatworms & 0.9 & 0.02 & 240 \\
\hline \multicolumn{4}{|l|}{ Echinoderm larvae } \\
\hline Bipinnaria & $0.5(2.5)$ & 0.009 & 300 \\
\hline Pentacula & $0.8(3.6)$ & 0.014 & $360-960$ \\
\hline Chaetognaths & $0.5(2.5)$ & 0.009 & 4200 \\
\hline Isopods & $0.3(1.4)$ & 0.005 & $540-980$ \\
\hline Cyprids & $0.3(1.4)$ & 0.005 & 1128 \\
\hline
\end{tabular}

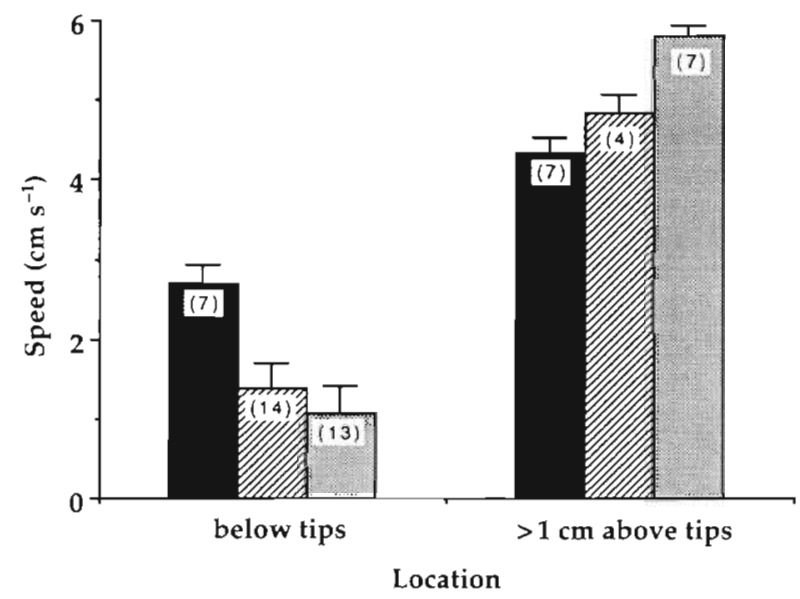

Fig. 7. Meandrina meandrites. Flow speed $\left(\mathrm{cm} \mathrm{s}^{-1}\right)$ as a function of vertical location above and horizontal position along the coral. Above: 1 to $2.5 \mathrm{~cm}$ above the tips of tentacles; below: at or below the tips of the tentacles; upstream (dark gray bars) includes positions up to $1 / 3$ coral length downstream of the upstream edge along the midline; middle (hatched bars) includes positions $1 / 3$ to $2 / 3$ along midline; downstream (light gray bars) includes all positions $>\frac{2}{3}$ along the midline; error bars represent $1 \mathrm{SE}$. Flow decelerated as water moved downstream below the tentacles (ANOVA: $F_{(2,33)}=7.5, \mathrm{p}=$ 0.0021 ) but accelerated as water moved downstream above the coral (ANOVA: $F_{(2,31)}=5.1, p=0.0125$ ). At all positions flow was significantly slower below the tentacles than above them (Mann-Whitney $U$-tests, all $\mathrm{p} \leq 0.001$ ) velocities greater than $5 \mathrm{~cm} \mathrm{~s}^{-1}$ (Scheffé Ftests based on assigning continuous velocity measurements to categories). A similar uniformity of capture rate was observed at the same experimental velocities for another horizontally oriented species of scleractinian coral (Agaricia agaricites) for whom feeding by gravitational deposition had been experimentally excluded (Helmuth \& Sebens 1993). Thus, increased capture rate for rightside-up corals feeding at low velocity could be accounted for by gravitational deposition of particles onto the corals' tentacles. This hypothesis is supported by close examination of the corals in Fig. 2, which reveals that many particles at or below the tentacle tips appear to be settling onto the coral surface.

Although these results were obtained with brine shrimp cysts, all the plankton shown in Table 1 can sink when not swimming and many, such as benthic foraminiferans, are nonswimmers. Many prey of Meandrina meandrites could thus be captured by gravitational deposition. Note that $75 \%$ of the diet of $M$. meandrites consisted of large calanoid copepods (923 to $1353 \mu \mathrm{m}$ in length), which can sink when not swimming. In fact, given the overrepresentation of the large calanoid copepod Calanopia sp. and the underrepresentation of the smaller cyclopoid copepod Oithona sp. in the coelenteron contents, it would be interesting to determine whether differential sinking rates or swimming behavior of these copepods played a role in their differential capture.

Shimeta \& Jumars (1991) further suggest that nutritionally important organic-mineral aggregates will tend to deposit by gravitational deposition but will be impossible to detect in gut contents. Since the intensity of gravitational deposition increases as the square of particle diameter (Rubenstein \& Koehl 1977), this mechanism should be most effective for larger prey/aggregates. Corals at depths $>15 \mathrm{~m}$ will experience slower, more unidirectional flow (Sebens \& Johnson 1991), and should be more likely to benefit from food captured by gravitational deposition and subsequently retained long enough to be ingested.

The dense thicket of long tentacles on the polyps of Meandrina meandrites probably contributes to retention of particles intercepted by gravitational deposition by slowing flow adjacent to the mouths of the polyps. Furthermore, the tentacles of $M$. meandrites are not evenly spaced. Rather, the mouths create gaps that are surrounded by rings of tentacles. These gaps may act as depositional pits and enhance feeding. For suspen- 

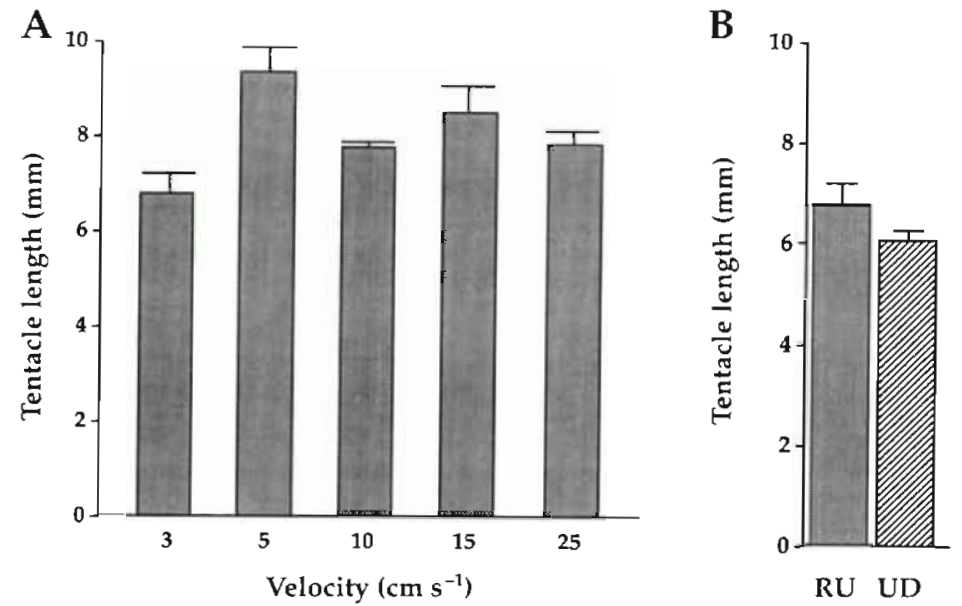

Fig. 8. Meandrina meandrites. Tentacle length $(\mathrm{mm})$ as a function of ambient velocity $\left(\mathrm{cm} \mathrm{s}^{-1}\right)$ comparing (A) corals oriented rightside-up and (B) corals feeding at $3 \mathrm{~cm} \mathrm{~s}^{-1}$ oriented rightside-up (RU, gray bar) and upside down (UD, hatched bar). Height of bars represent mean tentacle length; error bars equal $1 \mathrm{SE}$. Tentacle length differed between veloci-

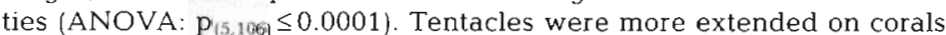
feeding at $5 \mathrm{~cm} \mathrm{~s}^{-1}$ than in the slowest flow $\left(3 \mathrm{~cm} \mathrm{~s}^{-1}\right.$; Scheffé $F$-test) and fastest flow (25 $\mathrm{cm} \mathrm{s}^{-1}$; Scheffé $F$-test). Tentacle length did not differ between corals which fed rightside-up and those which fed upside down at $3 \mathrm{~cm} \mathrm{~s}^{-1}$ (Fisher's PLSD)

sion feeders that rely on the flux of neutrally buoyant suspended particles carried in flow, lower fluid and particle flux can result in a decreased rate of food availability (fewer food particles per time) at the level of the tentacles (McFadden 1986, Shimeta \& Jumars 1991). However, for suspension feeders that rely on the deposition of food particles onto their feeding surface, low flux environments will not alter the rate of encounter of particles by deposition (Rubenstein \& Koehl 1977), but will enhance retention of particles deposited in that area.

As more benthic particles become resuspended in faster flow, the concentration of particles carried into an array of tentacles by flow should increase. Concurrently, mechanisms that rely on particles running into the tentacles along a horizontal axis (e.g. inertial impaction and direct interception; sensu Rubenstein \& Koehl 1977) should also become relatively more important in faster flow. Although the number of particles available for capture per unit time and the effectiveness of inertial impaction as a mechanism of particle capture increase as water flux increases (Rubenstein \& Koehl 1977), particles can become more difficult to retain, as they impact the tentacles with greater inertia and are subsequently dislodged by drag. The inability of tentacles to retain captured particles, coupled with deformation (Fig. 2A) and shortening of upstream tentacles, may account for the lower capture rates observed at higher velocities.

\section{Feeding rate was independent of horizontal planform area}

A multiple regression (using original velocity measurements, not velocity categories) of cyst capture as a function of flow speed and horizontal planform colony area (projected area parallel to flow) revealed that wholecolony capture rate of Meandrina meandrites was independent of planform colony area (partial $F_{\left(2.17_{i} \text { velocity) }\right.}=6.48, \mathrm{p}=0.021 ;$ partial $\left.F_{(2,17, \text { area })}=0.69, \mathrm{p}=0.42\right)$.

Although the range of colony size was small (limited by the size of the flow tank), the lack of association between feeding rate and planform colony area was somewhat surprising. Unless upstream polyps depleted particles available to downstream polyps, a larger horizontal planform area of coral would be expected to capture more particles as a simple mechanical consequence of intercepting a greater volume of water and thereby a greater number of particles.

This result could be explained by differential feeding rates between the edges and middle of colonies. When the edge feeds more efficiently than the middle, whole-colony feeding rates should decrease with increasing colony size because the relative proportion of edge to middle decreases. This phenomenon has been observed for arborescent bryozoans (Okamura 1984), for alcyonacean soft corals (Patterson 1984, McFadden 1986), for individual branches of gorgonian corals (Lasker 1981, Witting \& Sebens unpubl.), and, by inference, for clumps within populations of phoronids (Johnson 1986). The following section examines differences in feeding rates of polyps occurring at different locations on colonies of Meandrina meandrites.

\section{Intercolony differences in location of capture}

To test for interaction between location of cyst capture and colony identity, all colonies at a given velocity were analyzed using a 2 -way ANOVA. The only significant interaction occurred at $5 \mathrm{~cm} \mathrm{~s}^{-1}$ $\left(p_{\left(12,107_{\text {interaction }}\right)}=0.0001\right)$. For this reason the data for $5 \mathrm{~cm} \mathrm{~s}^{-1}$ were not pooled in later analyses to test for locational differences.

ANOVA revealed that at $5 \mathrm{~cm} \mathrm{~s}^{-1}$ there were no significant differences in mean per polyp capture rate for any of these colonies $\left(p_{(4,1.22)}=0.66\right)$. Therefore, significant interaction at this velocity was interpreted to mean that location of highest cyst capture was variable between colonies tested at $5 \mathrm{~cm} \mathrm{~s}^{-1}$. Decreased feeding 

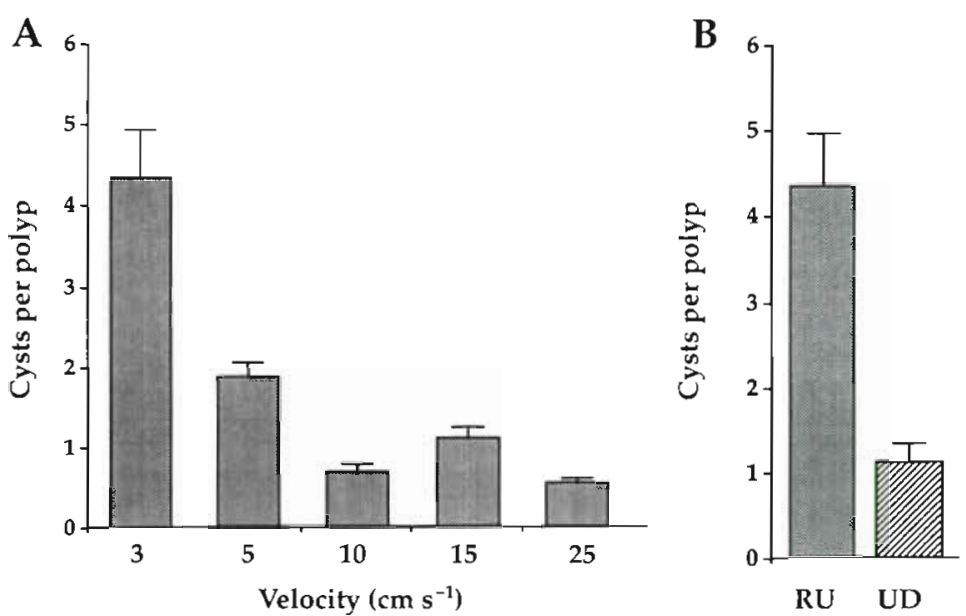

Fig. 9. Meandrina meandrites. Histogram of feeding rates (mean number of cysts captured per polyp) as a function of velocity $\left(\mathrm{cm} \mathrm{s}^{-1}\right)$, comparing (A) corals oriented rightside-up and (B) corals feeding at $3 \mathrm{~cm} \mathrm{~s}^{-1}$ oriented rightside-up (RU, gray bar) and upside down (UD, hatched bar). Height of bars represent mean number of cysts captured per polyp; error bars = $1 \mathrm{SE}$. Regression analysis (using original velocity measurements, not velocity categories) revealed a negative association between per polyp cyst capture and increasing flow speed $\left(R^{2}=0.13\right.$; $\left.\mathrm{p}_{(1,471)} \leq 0.0001\right)$ for corals oriented rightside-up. At $3 \mathrm{~cm} \mathrm{~s}^{-1}$, per polyp cyst capture of upside-down corals was less than that of corals feeding rightside-up (ANOVA assigning continuous measurements to categories: $\left.\mathrm{p}_{(1,159)}=0.0001\right)$

rates and variability in location of particle capture at $5 \mathrm{~cm} \mathrm{~s}^{-1}$ suggest that feeding by mechanisms other than gravitational deposition probably becomes important around $5 \mathrm{~cm} \mathrm{~s}^{-1}$, and that intercolony differences, such as size, shape, or tentacle extension, may contribute to variation in capture success of the polyps feeding in different positions on the colonies. For example, at $5 \mathrm{~cm} \mathrm{~s}^{-1}$ tentacles were longer (Fig. 8) and more variably pressed against the upstream edge on corals (Fig. 2) than at other faster or slower ambient velocities.

\section{Locational differences in feeding rates occurred at lowest velocity}

Although there were no significant interactions between colony and location of capture success at any velocity other than $5 \mathrm{~cm} \mathrm{~s}^{-1}$ (see previous section), there were both between-location $\left(\mathrm{p}_{(3,80 \text {; location })}=0.014\right)$ and between colony effects $\left(p_{(3,80 ; \text { colony })}=0.018\right)$ in per polyp capture rates at the lowest velocity. Betweencolony effects at this low flow were due to poor capture by 1 colony. Therefore, to analyze which locations on colonies were associated with differential capture rates, only those colonies that fed well and whose mean per polyp capture rates were not significantly different from each other were examined at this flow speed. With the exception of the colonies tested at $5 \mathrm{~cm} \mathrm{~s}^{-1}$, each of the colonies at a given velocity was then treated as a replicate for that velocity.

There were positional differences in per polyp capture rates at the lowest velocity (Fig. 10). For rightside-up corals capture rate was highest at the leading edge and in the middle of colonies, whereas for upside-down corals only the upstream edge of colonies maintained a higher capture rate. At all faster velocities (not including $5 \mathrm{~cm} \mathrm{~s}^{-1}$ ), per polyp capture rate was independent of location on the colony.

Two mechanisms could account for the locational differences in capture success observed in the slowest flow. (1) Particles with relatively low inertia probably ran into and adhered to the upstream edge of colonies. This hypothesis is supported by the occurrence of higher capture rates on the upstream edge of corals oriented both upside down and rightside-up, and has also been observed for another species of scleractinian coral (Helmuth \& Sebens 1993), 2 species of alcyonacean soft corals (Patterson 1984, McFadden 1986), and for branching bryozoans (Okamura 1984), but not for branching gorgonians (Lasker 1981). It is unlikely that bedload transport of sunken cysts contributed to these phenomena as the tentacles of all except one of the corals feeding at the lowest velocity were $>2 \mathrm{~cm}$ from the bottom of the flow tank. (2) Particles that are gravitationally deposited will have a relatively high rate of retention in the middle of colonies at slow flows. This hypothesis is supported by the disappearance of increased capture rates in the middle of colonies oriented upside down. Gravitational deposition has not been documented as an important mechanism of particle capture for other suspension feeders, but is likely to be of importance to the capture of detritus, such as parts of crustaceans, by zoanthids (Koehl 1977 a, Rubenstein \& Koehl 1977, Sebens 1977), or by actinarians (sea anemones such as Anthopleura xanthogrammica) that orient their crown of tentacles horizontally (Koehl 1977b). Encrusting bryozoans also experience slow flow during portions of their feeding cycle (Okamura 1985) and can certainly respond strongly to the deposition of food and detritus upon their surfaces (Winston 1979).

The uniformity of capture rate over entire colonies at higher velocities suggests that the high speed at which particles move relative to the corals' ability to retain them dominates capture rate of Meandrina meandrites at velocities $\geq 10 \mathrm{~cm} \mathrm{~s}^{-1}$. Decrease in the effectiveness of gravitational deposition and upstream capture, due 
A

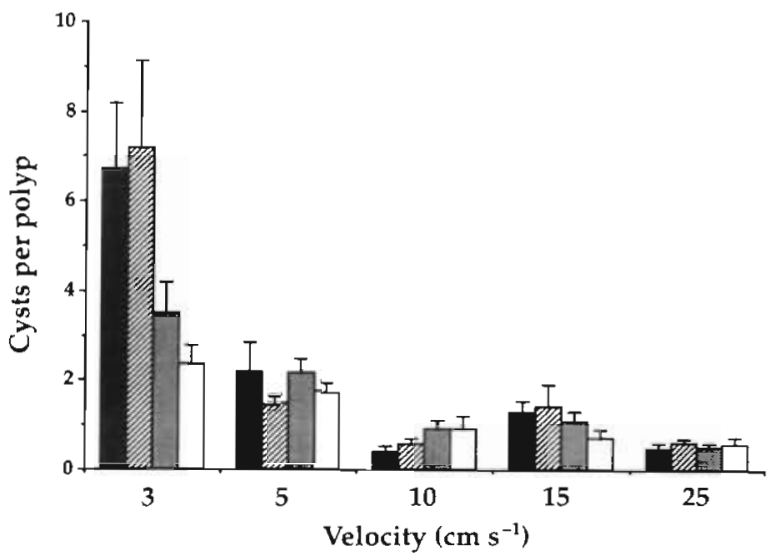

Fig. 10. Meandrina meandrites. Histogram of feeding rates (mean number of cysts captured per polyp) as a function of velocity $\left(\mathrm{cm} \mathrm{s}^{-1}\right)$ in the following locations: upstream edges (dark gray bars), middles (hatched bars), sides (light gray bar) and downstream edges (clear bars) for (A) corals oriented rightside-up and (B) corals oriented upside down feeding at $3 \mathrm{~cm} \mathrm{~s}^{-1}$. Positional differences were significant only at the lowest velocity (ANOVA: $\mathrm{p}_{(3,64 \text {, rightside-up) }}=0.006 ; \mathrm{p}_{(3,60 ;}$ upside down) $=$ 0.0001 ). On rightside-up corals feeding at $3 \mathrm{~cm} \mathrm{~s}^{-1}$ capture rate was highest at the leading edge and in the middle of colonies (Fisher's PLSD: leading edge >down-

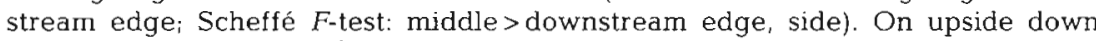
corals feeding at $3 \mathrm{~cm} \mathrm{~s}^{-1}$ only the upstream edge of colonies maintained a higher capture rate (Scheffé F-test: upstream edge > middle, side, downstream edge). At all faster velocities (not including $5 \mathrm{~cm} \mathrm{~s}^{-1}$ ) capture rate was independent of location on colony (ANOVA: $\left.\mathrm{p}_{\left(3,79,10 \mathrm{~cm} \mathrm{~s}^{-1}\right)}=0.20 ; \mathrm{p}_{\left(3.49 ; 15 \mathrm{~cm} \mathrm{~s}^{-1}\right)}=0.36 ; \mathrm{p}_{\left(2.109 ; 25 \mathrm{~cm} \mathrm{~s}^{-1}\right)}=0.90\right)$

both to the greater inertia of particles blown past the upstream edge as well as to the deformation of tentacles against the upstream edge of corals (Fig. 2A), may account for the disappearance of locational capture success in these faster flows.

\section{Horizontal morphology prohibits increased downstream capture?}

One surprising result of this study was that, despite a fairly broad region of slowed erratic water movement on the downstream edge of colonies of Meandrina meandrites (Fig. 2), there was never any feeding advantage to polyps located on the downstream edge of these colonies at any flow speed. This result is in contrast to the results of other studies that have observed positional differences in feeding performance (Lasker 1981. Okamura 1984, Patterson 1984, McFadden 1986, Holland et al. 1987, Witting \& Sebens unpubl.). Although it is generally accepted that tentaculate suspension feeders (that do not have their tentacles enclosed within a shell) should benefit when feeding from the slowed erratic water movement in their downstream wake (general: Wainwright et al. 1976, Warner 1977; corals: Leversee 1976; alcyonacean soft corals: Patterson 1984, McFadden 1986; polychaetes: Carey 1983, Merz
B

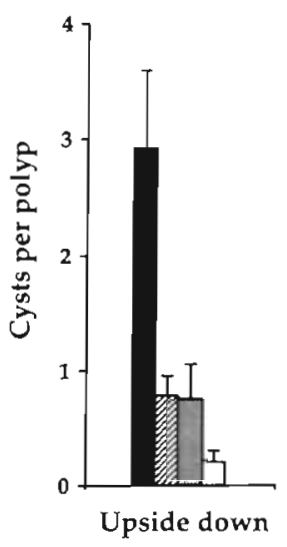

1984; arborescent bryozoans: Okamura 1984, 1988, 1990; phoronids: Johnson 1988, 1990; crinoids: Holland et al. 1987), the results of our study suggest that the morphology of the downstream edge of such colonies is critical to the effectiveness of particle capture from a wake.

Colonies that live in strongly bior uni-directional flow often exhibit a vertically planar morphology that is thought to be associated with capture of food particles from the region of the downstream wake (summarized in Wainwright et al. 1976, Wainwright \& Koehl 1976, Warner 1977, Patterson 1980). We found that although Meandrina meandrites lives in areas of strongly bidirectional flow, it exhibits a generally rounded morphology. These results suggest that there should be a decrease in advantage to feeding from a downstream wake as the orientation of feeding units shifts towards a more horizontal position, and that such horizontally oriented suspension feeders should exhibit much less directional bias in their orientation to currents.

It is tempting to conclude from these results that horizontal morphology alone inhibits enhanced downstream capture from a wake. These results, however, are in contrast to those obtained for another scleractinian with a flattened morphology (Agaricia agaricites; Helmuth \& Sebens 1993) for which there was enhanced downstream capture in faster flows. In Helmuth \& Sebens' (1993) study, however, gravitational deposition was factored out and the length of tentacles was short relative to the ridges on the surface of the coral. As discussed above, relatively long tentacles will act to slow flow close to the corals' surface and may enhance retention of particles in areas upstream of the wake. Thus, relatively long tentacles coupled with a horizontal morphology perhaps act as much to enhance relative upstream retention of food particles as to inhibit downstream capture, such that differences normally attributed to enhanced downstream capture disappear.

\section{Feeding in the field}

The results of this study generate a number of hypotheses concerning how Meandrina meandrites feeds 
under natural field conditions. It does not, however, consider the relative importance of prey that swim without sinking. Velocity-related effectiveness of the capture of non-sinking prey that swim remains an open question.

Although flow speed is highly variable, there were always periods of slow flow $\left(<4 \mathrm{~cm} \mathrm{~s}^{-1}\right)$ during our field flow measurements (i.e. Fig. 6). Only very slow flow produced locational differences in per polyp capture rates in our experiments. Areas of a colony that capture more food in slower flow (upstream and middle) should capture the most particles overall, because in faster flow all positions do equally well. However, most colonies live in oscillating flow (Fig. 6), so that upstream and downstream edges alternate. In addition, sides become upstream or downstream edges some of the time, and generally experience slow flow at that time (Fig. 6B). To understand how locational capture success might affect the overall capture of sinking or neutrally buoyant prey, it would be necessary to integrate average direction and speed of flow to determine how much time any portion of the colony is feeding from a given flow direction in slow flows. Since there are locational differences in capture rate, a coral might adjust whole-colony capture by changing its shape to adjust the proportion of each location. Thus, it is possible that even the morphology of a rigid, flattened coral with elongate tentacles might be fine-tuned to local flow conditions.

Acknowledgements. We thank the members of the 'Aquarius' research team: R. Aiello-Allmon, D. Kesling, T. Loher, T. Maney, J. Miles, L. Savina and S. Zamojski for many late hours of laboratory assistance. We also thank the staff of the NOAA/NURP program and of the West Indies Laboratory for their generous help; D. Ritchie for building the model corals and assisting with subsequent data collection and analysis; and A. Gauzens and E. Porter for zooplankton identification. This manuscript has been improved by critical readings by K. Durante, O. Ellers, J. Gosline, S. Katz, M. Lillie, B. Okamura, C. Pollack and 4 anonymous reviewers. This research was supported by a National Oceanic and Atmospheric Administration National Undersea Research Center-Fairleigh Dickinson University Hydrolab Mission grant to K.S. and Northeastern University and NATO postdoctoral fellowships to A.J. This is contribution no. 201 from the Marine Science Center at Nahant.

\section{LITERATURE CITED}

Best, B. A. (1988). Passive suspension feeding in a sea pen: effects of ambient flow on volume flow rate and filtering efficiency. Biol. Bull. 175: 332-342

Boyd, C. M. (1973). Small-scale spatial patterns of marine zooplankton examined by an electronic, in situ, zooplankton collecting device. Neth. J. Sea Res. 7: 103-111

Carey, D. A. (1983). Particle resuspension in the benthic boundary layer induced by flow around polychaete tubes Can. J. Fish. Aquat. Sci. 40: 301-308
Chamberlain, I. A., Graus, R. R. (1975). Water flow and hydromechanical adaptations of branched reef corals. Bull. mar. Sci. 25: 112-125

Denny, M. W. (1988). Biology and the mechanics of waveswept environments. Princeton University Press, Princeton, NJ

Eckman, J. E., Nowell, A. R. M., Jumars, P. A. \{1981\}. Sediment destabilization by animal tubes. J. mar. Res. 39: 361-374

Graus, R. R., Chamberlain, J. A., Boker, A. M. (1977). Structural modifications of corals in relation to waves and currents. Stud. Geol. Am. Ass. Petrol. Geol. 4: 135-153

Grigg, R. W. (1972). Orientation and growth form of sea fans Limnol. Oceanogr. 17: 185-192

Harvell, C. D., LaBarbera, M. (1985). Flexibility: a mechanism for control of local velocities in hydroid colonies. Biol. Bull. 168: $312-320$

Helmuth, B., Sebens, K. (1993). The influence of colony morphology and orientation to flow on particle capture by the scleractinian coral Agaricia agaricites (Linnaeus) J. exp. Mar. Biol. Ecol. 165: 251-278

Holland, N. D., Leonard, A. B., Strickler, R. J. (1987). Upstream and downstream capture during suspension feeding by Oligometra serripinna (Echinodermata: Crinoidea) under surge conditions. Biol. Bull. 173: 552-556

Hunter, T. (1989). Suspension feeding in oscillating flow: the effect of colony morphology and flow regime on plankton capture by the hydroid Obelia longissima. Biol. Bull. 176: 41-49

Johnson, A. S. (1986). Consequences of individual and group morphology: a hydrodynamic study of the benthic suspension feeder Phoronopsis viridis. Ph.D. thesis, University of California, Berkeley

Johnson, A. S. (1988). Hydrodynamic study of the functional morphology of the benthic suspension feeder Phoronopsis viridis (Phoronida). Mar, Biol. 100: 117-126

Johnson, A. S. (1990). Flow around phoronids: consequences of a neighbor to suspension feeders. Limnol. Oceanogr. 35 1395-1401

Koehl, M. A. R. (1977a). Water flow and the morphology of zoanthid colonies. Proc. 3rd int. Symp. coral Reefs 1: $437-444$

Koehl, M. A. R. (1977b). Mechanical organization of cantileverlike sessile organisms: sea anemones. J. exp. Biol. 69: $127-142$

Lasker, H. R. (1981). A comparison of the particulate feeding abilities of three species of gorgonian soft coral. Mar. Ecol. Prog. Ser. 5: 61-67

Leversee, G. J. (1976). Flow and feeding in fan-shaped colonies of the gorgonian coral, Leptogorgia. Biol. Bull. 151: $344-356$

Lewis, J. B., Price, W. S. (1975). Feeding mechanisms and feeding strategies of Atlantic reef corals. J. Zool., Lond. 176: $527-544$

McFadden, C. S. (1986). Colony fission increases particle capture rates of a soft coral: advantages of being a small colony. J. exp. mar. Biol. Ecol. 103: 1-20

Merz, R. A. (1984). Self-generated versus environmentally produced feeding currents: a comparison for the sabellid polychaete Eudistylia vancouveri. Biol. Bull. 167: 200-209

Muscatine, L. (1973). Nutrition of corals. In: Jones, O. A., Endean, R. (eds.) Biology and geology of coral reefs, Vol. 2. Academic Press, New York, p. 79-115

Nowell, A. R. M., Church, M. (1979). Turbulent flow in a depthlimited boundary layer. J. geophys. Res. 84: 4816-4824

Nowell, A. R. M., Jumars, P. A. (1984). Flow environments of the aquatic benthos. A. Rev. Ecol. Syst. 15: 303-328 
Okamura, B. (1984). The effects of ambient flow velocity, colony size, and upstream colonies on the feeding success of Bryozoa. I. Bugula stolonifera Ryland, an arborescent species. J. exp. mar. Biol. Ecol. 83: 179-193

Okamura, B. (1985). The effects of ambient flow velocity, colony size, and upstream colonies on the feeding success of Bryozoa. II. Conopeum reticulum (Linnaeus), an encrusting species. J. exp. mar. Biol. Ecol. 89: 69-80

Okamura, B. (1988). The influence of neighbors on the feeding of an epifaunal bryozoan. J. exp. mar. Biol. Ecol. 120: $105-123$

Okamura, B. (1990). Behavioural plasticity in the suspension feeding of benthic animals. In: Hughes, R. N. (ed.) Behavioural mechanisms of food selection. NATO ASI Ser. G20: $637-660$

Patterson, M. R. (1980). Hydromechanical adaptations in Alcyonium siderium (Octocorallia). In: Schneck, D. J. (ed.) Biofluid mechanics, Vol. 2. Plenum Press, New York, p. 183-201

Patterson, M. R. (1984). Patterns of whole colony prey capture in the octocoral, Alcyonium siderium. Biol. Bull. 167: $613-629$

Porter, J. (1974). Zooplankton feeding by the Caribbean reefbuilding coral Montastrea cavernosa. Proc. 2nd int. Symp. coral Reefs 1: 111-125

Rees, J. T. (1972). The effect of current on the growth form in an octocoral. J. exp. mar. Biol. Ecol. 10: 115-124

Riedl, R. J. (1971). Water movement. In: Kinne, O. (ed.) Marine ecology, Vol. 1(2). Wiley Interscience, London, p. $1085-1088,1124-1156$

Rubenstein, D. I., Koehl, M. A. R. (1977). The mechanisms of filter feeding: some theoretical considerations. Am. Nat. 111: 981-994

Rutzler, K., Ferraris, J. D., Larson, R. L. (1980). A new plankton sampler for coral reefs. P.S.Z.N. I: Mar. Ecol. 1: 65-71

Sebens, K. P. (1977). Autotrophic and heterotrophic nutrition of coral reef zoanthids. Proc. 3rd int. Symp. coral Reefs 1. 397 406

Sebens, K. P. (1987). Coelenterate energetics. In: Vernberg, F. J., Pandian, T. J. (eds.) Animal energetics. Academic Press, New York, p. 55-120

Sebens, K. P., DeRiemer, K. (1977). Diel cycles of expansion and contraction in coral reef anthozoans. Mar. Biol. 43: $247-256$

Sebens, K. P., Johnson, A. S. (1991). Effects of water movement on prey capture and distribution of reef corals. Hydrobiologia 226: 91-101

This article was presented by J. S. Pearse, Santa Cruz, California, USA
Sebens, K. P., Koehl, M. A. R. (1984). Predation on zooplankton by the benthic anthozoans Alcyonium siderium (Alcyonacea) and Metridium senile (Actinaria) in the New England subtidal Mar. Biol. 81: 255-271

Sebens, K. P., Maney, E. J. (1992). A portable diver-operated plankton sampler for near-substratum use. In: Cahoon, L. B. (ed.) Diving for science 1992. Proc. Am. Acad. Underwat. Sci., 12th A. Symp., Wilmington, NC

Shimeta, J., Jumars, P. A. (1991). Physical mechanisms and rates of particle capture by suspension-feeders. Oceanogr mar. Biol. A. Rev. 29: 191-257

Sokal, R. R., Rohlf, F. J. (1981). Biometry. W. H. Freeman \& Co., San Francisco

Théodor, J., Denizot, M. (1965). Contribution à l'étude des gorgones. I. A propos de l'orientation d'organismes marins fixés végétaux et animaux en fonction du courant. Vie Milieu 16: 237-241

Velimirov, B. (1976). Variation in forms of Eunicella cavolini Koch (Octocorallia) related to intensity of water movement. J. exp. mar. Biol. Ecol. 21: 109-117

Vogel, S. (1981). Life in moving fluids. Princeton University Press, Princeton, NJ

Vogel, S., LaBarbera, M. (1978). Simple flow tanks for research and teaching. BioSci. 28: 638-643

Wainwright, S. A. (1967). Diurnal activity in hermatypic gorgonians. Nature 216: 1041

Wainwright, S. A., Biggs, W. D., Currey, J. D., Gosline, J. M. (1976). Mechanical design in organisms. Edward Arnold, London

Wainwright, S. A., Dillon, J. R. (1969). On the orientation of sea fans (genus Gorgonia). Biol. Bull. 136: 130-139

Wainwright, S. A., Koehl, M. A. R. (1976). The nature of flow and reaction of benthic cnidaria to it. In: Mackie, G. O. (ed.) Coelenterate ecology and behavior. Plenum Press, New York, p. 5-21

Warner, G. F. (1977). On the shapes of passive suspension feeders. In: Keegan, B. F., Ceidigh, P. O., Boaden, P. J. S. (eds.) Biology of benthic organisms. Proc. 11th Eur. mar. biol. Symp. Pergamon Press, Oxford, p. $567-576$

Wellington, G. M. (1982). An experimental analysis of the effects of light and zooplankton on coral zonation. Oecologia 52: 311-320

Winston, J. E. (1979). Current-related morphology and behavior in some Pacific coast bryozoans. In: Larwood, G. P., Abbott, M. B. (eds.) Advances in bryozoology. Academic Press, London, p. 247-268

Manuscript first received: April 1, 1993

Revised version accepted: June 17, 1993 